\title{
In Vitro Evaluation of Antioxidant Activity of Homeopathic Mother Tincture and Total Phenolic Content
}

\author{
Shifa Shaffique ${ }^{1, *}$, Haseeb Anwer ${ }^{1}$, Hafiz Muhammad Asif ${ }^{2}$, Muhammad Akram $^{3}$, Anila Rehman $^{2}$, Saeed \\ Ahmed $^{2}$, Khalil Ahmed ${ }^{2}$ \\ ${ }^{1}$ Department of Physiology, Faculty of Life Sciences, Government College University, Faisalabad, Pakistan \\ 2University College of Conventional Medicine, Faculty of Pharmacy and Alternative Medicine, The Islamia \\ University of Bahawalpur, Pakistan \\ ${ }^{3}$ Department of eastern medicine, government college university Faisalabad
}

Authors' Contributions

1,3,6 Design the study

2 Generated the idea to consider this study

4,7 Help in data collection

5 Processed and executed the designed work

6 Supervised in data analysis

\section{Article info.}

Received: December 10, 2018

Accepted: March 03, 2020

Funding Source: Nil

Conflict of Interest: Nil

Cite this article: Shaffique $S$, Anwer $\mathrm{H}$, Asif

HM, Akram M, Rehman A, Ahmed S, Ahmed

K. In Vitro Evaluation of Antioxidant Activity of

Homeopathic Mother Tincture and Total

Phenolic Content. RADS J Pharm Pharm Sci.

2020; 8(1):26-30

*Address of Correspondence Author: Shifa.shafiquee@gmail.com

\section{A BSTRACT}

Background: Antioxidants are those compounds which scavengers the free radicals, widely used in health protection and prescribed on large scale in biomedical health care units. In homeopathic system of medicine mother tinctures are prescribed. Mother tinctures of medicinal plants are having the potential to treat the various acute and chronic ailments.

Objectives: The present study was accompanied to determine the total phenolic content and the antioxidant activity of homeopathic mother tincture of plant origin i.e. Baptisia tinctoria, Berberis aquifolium, Echinacea angustifolia, Hydrangea arborescens, Hydrastis canadensis, Kreosotum, and Thuja occidentalis in comparison with ascorbic acid.

Methods: Antioxidant activity was evaluated by 2, 2-diphenyl-1-picrylhydrazyl (DPPH) inhibition assay method. A volume of $0.1 \mathrm{mM}$ solution of DPPH was used while mother tinctures $(1.25,5,2.5 \mu$ l volumes) were used for evaluation of antioxidant activity. Ascorbic acid was taken as a standard control and alcohol as negative control in antioxidant activity protocol. Total phenolic content was measured by Folin-Ciocalteu reagent assay. Total phenolic content of mother tinctures was measured in comparison with ascorbic acid.

Results: All tested homeopathic mother tinctures of plant origin showed significant antioxidant potential except Hydrangea arborescens and Kreosotum. Alcohol which was used as negative control exhibited no antioxidant activity. Pulsatilla nigricans possess highest antioxidant potential $85 \pm 0.3$ among other tested mother tinctures against DPPH free radical and $98.8 \pm 2$ maximum no of phenolic contents.

Conclusion: Homeopathic Mother Tinctures of plant origin showed antioxidant activity due to presence of phenolic content.

Key words: Antioxidant, Homeopathic tinctures, Total phenolic contents. 


\section{INTRODUCTION}

Free radicals are uncharged molecules they can damage the cell of organism by damaging the DNA. Free radicals also caused the oxidative stress by chain reactions [1]. Antioxidants are those substances which inhibit the process of oxidation [2, 3]. These are natural as well as the synthetic substances [4, 5]. Natural antioxidant have their potential to kill the free radicals due to presence of phenolic contents. In homeopathic system of medicine mother tinctures are prescribed. Homeopathic mother tinctures having potential to prevent oxidation present study was conducted to determine the antioxidant activity of homeopathic mother tinctures [6]. Homeopathic mother tinctures are in liquid form, prepared by the use of suitable concentration of alcohol treated with raw material (which may be fresh or dried). There are different methods for preparation of homeopathic mother tinctures depending upon nature of the raw material. Homeopathic mother tinctures are obtained by the methods of maceration, digestion, infusion, decoction and fermentation [7]. Homeopathic mother tinctures of plant origin carry the hydro-alcoholic extracts of medicinal plant. The major difference between the mother tincture and simple extract is the ratio of alcohol with medicinal substance. Homeopathic mother tinctures prepared by treating one part of medicinal substance with nine parts of alcohol where as simple extract comprises on one part of medicinal substance and 4 or 5 parts of alcohol. Theta $\Phi$, or $Q$ symbol is used to represent the homeopathic mother tincture [8-10]. Experimental mother tinctures were Berberis aquifolium, Baptisia tinctoria, Echinacea angustifolia, Hydrastis canadensis, Hydrangea arborescens, Kreosotum, and Thuja occidentalis.

\section{METHODOLOGY}

\section{2, 2-Diphenyl-1-picrylhydrazyl free radical scavenging assay}

In current study, antioxidant activity of homeopathic mother tinctures was tested with free radical 2, 2 diphenyl 1-picrylhydazyl method. In present study 2, 2 diphenyl 1-picrylhydazyl is used in present study due to its certain advantage over other used methods. Evaluation of antioxidant activity through 2, 2 diphenyl 1-picrylhydazyl (DPPH) inhibition assay is a simple and cost effective method [11]. The other advantage of DPPH inhibition assay is lying in its ability to measure total antioxidant capacity of extract or mother tincture as it is not specific to any antioxidant constituent [12]. The scavenging activity of homoeopathic mother tinctures was checked with DPPH radical technique. A volume of $0.1 \mathrm{mM}$ solution of DPPH was prepared by adding $25 \mathrm{mg}$ of DPPH in $100 \mathrm{ml}$ of methanol. A micro assay of antioxidant evaluation was used with slight modifications [9]. A volume of $90 \mu \mathrm{l}$ of DPPH solution with subsequent different serial dilutions $(5,2.5$, and $1.25 \mu \mathrm{l})$ of mother tincture were placed in wells of a 96-well micro plate. The wells containing DPPH and $10 \mu \mathrm{l}$ of ethanol were used as negative control. Gallic acid was taken as standard control. The whole process was done in triplicate. The reaction mixture was placed for $30 \mathrm{~min}$ at $37^{\circ} \mathrm{C}[13,14]$. The absorbance was measured at $517 \mathrm{~nm}$ using Biotech ELISA micro plate reader. The absorbance was taken as follows.

Scavenging activity $\%=([\mathrm{Ac}-\mathrm{Am} . \mathrm{t}) / \mathrm{Ac}] \times 100$ Where,

$A c=$ Absorbance of negative control

Am. $t=$ Absorbance of mother tincture

\section{Evaluation of total phenolic contents}

Total phenolic content was estimated by FCR (Sigma-Aldrich, Germany) using the methodology of McDonald [15]. A volume of $5 \mu \mathrm{l}$ of homeopathic mother tinctures and $50 \mu \mathrm{l}$ of $1 \mathrm{mM}$ sodium carbonate were added and then Folin-Ciocalteu $20 \%$ was added to make the volume up to $150 \mu \mathrm{l}$ in 96-well plate, and after incubating at $40^{\circ} \mathrm{C}$, the absorbance was checked at $479 \mathrm{~nm}$ [16].

\section{Statistical analysis}

The results were analysed by Descriptive statistics was used to represent data in the form of Mean $\pm S . E . M$ (Standard error of mean) between antioxidant activity by DPPH assay and total phenolic content ofmothertinctures. Significance levelwasset at $P \leq 0.05$.

2,2-Diphenyl-1-picrylhydrazyl free radical scavenging

assay

The scavenging activity of homoeopathic mother tinctures was 2, 2-Diphenyl-1-picrylhydrazyl free radical scavenging assay 2,2-Diphenyl-1-picrylhydrazyl free radical scavenging 
Assay 2,2-Diphenyl-1-picrylhydrazyl free radical scavenging assay.

\section{RESULTS AND DISCUSSION}

Pulsatilla nigricans possess highest antioxidant potential among other tested mother tinctures against DPPH free radical. All the other mother tinctures also have good antioxidant activity except Hydrangea arborescens and Kreosotum that are weak antioxidants [17, 18] as described in Table 1. Flavonoids and phenolic compounds present in tinctures and extracts possess strong antioxidant potential. Poly phenolic compounds are more potent antioxidant as compared to mono-phenols [19].

Thuja occidentalis, Hydrastis canadensis, Hypericum perforatum, Eucalyptus globulus, Baptisia tinctoria, Echinacea augustifolia and Berberis aquifolium also showed marvelous antioxidant potential with inhibition of DPPH in descending order in range of $74 \pm 0.03$ to $84.8 \pm 0.6 \%$. This study expressed $73.35 \%$ inhibition of DPPH by tested extracts at $75 \mu \mathrm{g} / \mathrm{ml}$ [20]) which is comparable with antioxidant result of present study regarding Thuja occidentalis mother tinctures, having higher (84.5\%) inhibition of DPPH that may due to use of high concentration of medicinal part in the preparation of mother tincture i.e. $100 \mu \mathrm{g} / \mathrm{ml}$ [21] as shown in Figure $1 .$.

Table 1. Results of mother tinctures, quercetin, and alcohol against 2 , 2-diphenyl-1-picrylhydrazyl.

\begin{tabular}{|c|c|}
\hline $\begin{array}{c}\text { Homeopathic mother } \\
\text { tinctures }\end{array}$ & $\begin{array}{c}\text { DPPH \% inhibition } \\
(\text { Mean } \pm \text { S.E.M }\end{array}$ \\
\hline Ascorbic acid & $92.7 \pm 0.3$ \\
\hline Alcohol & Nil \\
\hline Baptisia tinctoria & $83.6 \pm 0.3$ \\
\hline Berberis aquifolium & $74 \pm 0.03$ \\
\hline Echinacea augustifolia & $76.6 \pm 0.6$ \\
\hline Eucalyptus globulus & $84.2 \pm 0.4$ \\
\hline Hydrangea arborescens & $31.4 \pm 0.5$ \\
\hline Hydrastis canadensis & $83.03 \pm 0.03$ \\
\hline Hypericum perforatum & $82.5 \pm 0.4$ \\
\hline Kreosotum & $38.8 \pm 1.4$ \\
\hline Pulsatilla nigricans & $85 \pm 0.3$ \\
\hline Thuja occidentalis & $84.8 \pm 0.6$ \\
\hline
\end{tabular}

* S.E.M - Standard error of mean $(n=3)$.
In a previous study, extracts of Hydrastis canadensis showed presence of phenolic compounds in it by using gas chromatography combined with mass spectrometry (GC-MS) Phenolic compounds have strong antioxidant potential and might be responsible for antioxidant potential of Hydrastis canadensis [22].

In a previous study it is documented that Liquid chromatography with mass selective (LC-MS) detected high content of flavonoids in Hypericum perforatum. Hypericum perforatum showed $79.2 \%$ inhibition of DPPH in a previous study [23]. The results are compareable to a present study that showed $82.5 \%$ inhibition of DPPH. Moreover, antioxidant capacity may be due to its flavonoid content. In another study, dose dependant effect of Hypericum perforatum against DPPH was detected and it inhibited $79 \%$ of DPPH free radical with an $\mathrm{IC}_{50}$ of $109 \mu \mathrm{g} / \mathrm{ml}$ [24] In present study, it is concluded that Pulsatilla nigricans contains highest content of phenolic compounds i.e. 98.8 2 as shown in Table 2.

The results of present study are also compareable to a previous study, Eucalytus globulus Labill leaves extracts were evaluated for their antioxidant potential and phenolic contents. HPLC/MS showed high concentration of phenolic contents, cheifly flavonoids. E. globulus expressed significant amount of hyperoside flavanoid $(666.42 \pm 5.02 \mu \mathrm{g} / \mathrm{g}$ dw plant material). E. globulus showed $61.1 \%$ inhibition of DPPH [25]. It is somewhat less than that showed in present study. Homeopathic mother tincture of $E$. globulus also contain gallic acid and protocatechuic acids in addition to hyperoside flavanoid [26] that might be responsible for more antioxidant potential of homeopathic mother tincture.

Table 2. Total phenolic content of homeopathic mother tinctures $5 \mu \mathrm{l}$ and alcohol.

\begin{tabular}{|c|c|}
\hline Tested Compounds & Phenolic Contents \\
\hline Alcohol & NIL \\
\hline Thuja occidentalis & $97.5 \pm 3$ \\
\hline Hydrastis canadensis, & $81.4 \pm 5$ \\
\hline Hypericum perforatum, & $79.4 \pm 4$ \\
\hline Eucalyptus globulus, & $77.6 \pm 3$ \\
\hline Baptisia tinctoria, & $88.6 \pm 3$ \\
\hline Echinacea augustifolia & $69.7 \pm 2$ \\
\hline Berberis aquifolium & $93.1 \pm 5$ \\
\hline Kreosotum & $41.3 \pm 4$ \\
\hline Hydrangea arborescens & $94.9 \pm 1$ \\
\hline Pulsatilla nigricans & $98.8 \pm 2$ \\
\hline
\end{tabular}




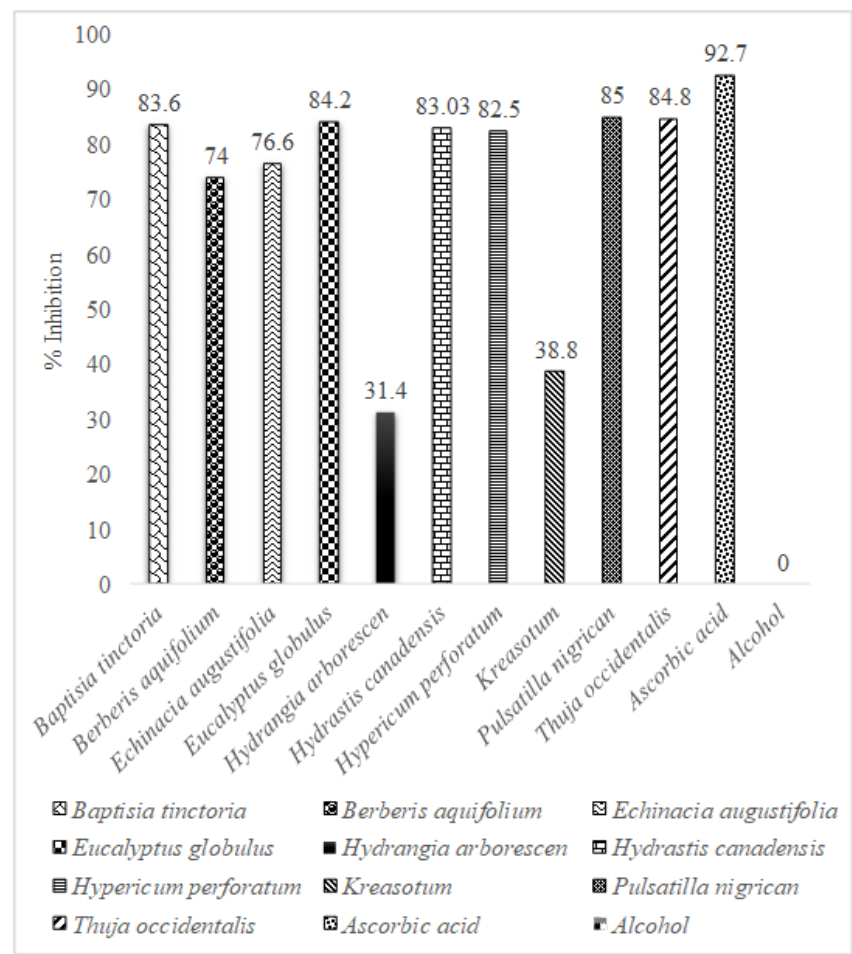

Figure 1. Graphical presentation of antioxidant activity of various homeopathic mother tinctures against DPPH.

Baptisia tinctoria contain alkaloids such as baptitoxine, glycosides like baptisin and baptin, isoflavones, flavonoids and polysaccharides. These active metabolites are responsible for its antioxidant potential [26].

In another study, Cichoric acid, echinacoside, cynarin, caffeic acid, chlorogenic acid and caftaric acid were identified and quantified in Echinacea roots. Analytical results revealed that roots of $E$. angustifolia contain $10.49 \mathrm{mg} / \mathrm{g}$ phenolic compounds. The current study showed $76.6 \%$ inhibition of DPPH. Echinacoside and cynarin are the pure compounds with marked antioxidant activity that are responsible for antioxidant activity of Echinacea [27].

The current study showed $74 \%$ inhibition of DPPH by Berberis aquifolium. In a previous study, berberine, jatrorrhizine, and magnoflorine in Berberis aquifolium (Mahonia aquifolium) have been studied that are responsible for its antioxidant potential [28-30].

\section{CONCLUSION}

Pulsatilla nigricans showed highest inhibition of DPPH (85\%) among other tested plant mother tinctures. It contains high content of flavonoids $98.8 \pm 2$ that might be responsible for its antioxidant activity.

\section{REFERENCES}

1. Rice-Evans C, Miller N, Paganga G. Antioxidant properties of phenolic compounds. Trends in plant science. 1997; 2(4):152-9.

https://doi.org/10.1016/S1360-1385(97)01018-2

2. Brand-Williams W, Cuvelier M-E, Berset C. Use of a free radical method to evaluate antioxidant activity. LWT-Food science and Technology. 1995; 28(1):25-30.

https://doi.org/10.1016/S0023-6438(95)80008-5

3. Halliwell B. Free radicals, antioxidants, and human disease: curiosity, cause, or consequence? The lancet. 1994; 344(8924):721-4.

https://doi.org/10.1016/S0140-6736(94)92211-X

4. Freeman BA, Crapo JD. Biology of disease: free radicals and tissue injury. Laboratory investigation; a journal of technical methods and pathology. 1982; 47(5):412-26.

5. Halliwell B, Gutteridge JM. [1] Role of free radicals and catalytic metal ions in human disease: an overview. Methods in enzymology. 186: Elsevier; 1990. p. 1-85.

https://doi.org/10.1016/0076-6879(90)86093-B

6. Ernst E. A systematic review of systematic reviews of homeopathy. British journal of clinical pharmacology. 2002; 54(6):577-82.

https://doi.org/10.1046/j.1365-2125.2002.01699.x

7. Aabel S. Homeopathy Research Evidence Base: References. Evid Based Complement Alternat Med. 2013; 2013:485272.

8. Biber A, Franck-Karl G, Waimer F, Riegert U, Wiget R. Analytical characterisation of homoeopathic mother tinctures. Pharmeuropa scientific notes. 2009; 2009(1):1-4.

9. Kay R, Bankaitis-Davis D. Method of characterizing a homeopathic preparation. Google Patents; 2003.

10. Shaffique S, Ahmed S, Hussain G, Rehman A, Anwar H. A novel approach of Homeopathy, Alternative to antibiotics. RADS Journal of Biological Research \& Applied Sciences. 2018; 9(1):50-2.

11. Bondet V, Brand-Williams W, Berset C. Kinetics and mechanisms of antioxidant activity using the DPPH. free radical method. LWT-Food Science and Technology. 1997; 30(6):609-15.

https://doi.org/10.1006/fstl.1997.0240

12. Kedare SB, Singh R. Genesis and development of DPPH method of antioxidant assay. Journal of food science and technology. 2011; 48(4):412-22. https://doi.org/10.1007/s13197-011-0251-1

13. Lee J, Chung H, Chang P-S, Lee J. Development of a method predicting the oxidative stability of 
edible oils using 2, 2-diphenyl-1-picrylhydrazyl (DPPH). Food chemistry. 2007; 103(2):662-9. https://doi.org/10.1016/j.foodchem.2006.07.052

14. Oh J, Kim E, Kim J, Kang J, Moon Y, Kang Y. Study on antioxidant potency of green tea by DPPH method. Journal of The Korean Society of Food Science and Nutrition. 2004.

15. Ismail A, Marjan ZM, Foong CW. Total antioxidant activity and phenolic content in selected vegetables. Food chemistry. 2004; 87(4):581-6.

https://doi.org/10.1016/j.foodchem.2004.01.010

16. Wojdyło A, Oszmiański J, Czemerys R. Antioxidant activity and phenolic compounds in 32 selected herbs. Food chemistry. 2007; 105(3):940-9.

https://doi.org/10.1016/j.foodchem.2007.04.038

17. Kähkönen MP, Hopia Al, Vuorela HJ, Rauha J-P, Pihlaja K, Kujala TS, et al. Antioxidant activity of plant extracts containing phenolic compounds. Journal of agricultural and food chemistry. 1999; 47(10):3954-62.

https://doi.org/10.1021/jf990146l

18. Molyneux $P$. The use of the stable free radical diphenylpicrylhydrazyl (DPPH) for estimating antioxidant activity. Songklanakarin J Sci Technol. 2004; 26(2):211-9.

19. Cao G, Sofic E, Prior RL. Antioxidant and prooxidant behavior of flavonoids: structure-activity relationships. Free Radical Biology and Medicine. 1997; 22(5):749-60.

https://doi.org/10.1016/S0891-5849(96)00351-6

20. Dubey S, Batra A. Role of phenolic compound rich ethanol fraction of Thuja occidentalis Linn. in protective mechanism. Journal of Pharmacy Research. 2009; 2(2):217-25.

21. Yogesh K, Ali J. Antioxidant potential of thuja (Thuja occidentalis) cones and peach (Prunus persia) seeds in raw chicken ground meat during refrigerated $\left(\begin{array}{lll}4 \pm 1 & C\end{array}\right)$ storage. Journal of food science and technology. 2014; 51(8):1547-53.

https://doi.org/10.1007/s13197-012-0672-5

22. Ahmad S, Rehman T, Abbasi WM, Zaman MM. Analysis of antioxidant activity and total phenolic content of some homoeopathic mother tinctures. Indian Journal of Research in Homoeopathy. 2017; 11(1):21.

https://doi.org/10.4103/0974-7168.200843
23. Orčić DZ, Mimica-Dukić NM, Francišković MM, Petrović SS, Jovin EĐ. Antioxidant activity relationship of phenolic compounds in Hypericum perforatumL. Chemistry Central Journal. 2011; $5(1): 34$. https://doi.org/10.1186/1752-153X-5-34

24. Benedí J, Arroyo R, Romero C, Martín-Aragón S, Villar AM. Antioxidant properties and protective effects of a standardized extract of Hypericum perforatum on hydrogen peroxide-induced oxidative damage in PC12 cells. Life sciences. 2004; 75(10):1263-76.

https://doi.org/10.1016/j.lfs.2004.05.001

25. Dezsi Ș, Bădărău $A S$, Bischin $C$, Vodnar $D C$, Silaghi-Dumitrescu R, Gheldiu A-M, et al. Antimicrobial and antioxidant activities and phenolic profile of Eucalyptus globulus Labill. and Corymbia ficifolia (F. Muell.) KD Hill \& LAS Johnson leaves. Molecules. 2015; 20(3):4720-34.

https://doi.org/10.3390/molecules20034720

26. Amol P, Vikas P, Kundan C, Vijay P, Rajesh C. In vitro free radicals scavenging activity of stems of Cuscuta reflexa. Journal of Pharmacy Research. 2009; 2(1).

27. Pellati $F$, Benvenuti $S$, Magro L, Melegari $M$, Soragni F. Analysis of phenolic compounds and radical scavenging activity of Echinacea spp. Journal of Pharmaceutical and Biomedical Analysis. 2004; 35(2):289-301.

https://doi.org/10.1016/S0731-7085(03)00645-9

28. Pyrkosz-Biardzka K, Kucharska AZ, SokółŁętowska A, Strugała P, Gabrielska J. A comprehensive study on antioxidant properties of crude extracts from fruits of Berberis vulgaris $L$., Cornus mas L. and Mahonia aquifolium Nutt. Polish Journal of Food and Nutrition Sciences. 2014; 64(2):91-9.

https://doi.org/10.2478/v10222-012-0097-x

29. Zheng W, Wang SY. Antioxidant activity and phenolic compounds in selected herbs. Journal of agricultural and food chemistry. 2001; 49(11):5165-70.

https://doi.org/10.1021/jf010697n

30. Pourmorad F, Hosseinimehr S, Shahabimajd N. Antioxidant activity, phenol and flavonoid contents of some selected Iranian medicinal plants. African journal of biotechnology. 2006; 5(11).

\footnotetext{
This is an Open Access article distributed under the terms of the Creative Commons Attribution License (http://creativecommons.org/licenses/by/4.0), which permits unrestricted use, distribution, and reproduction in any medium, provided the original work is properly cited.
} 